\title{
Prevalence of anemia among pregnant women in rural Koppal: a study from teaching hospital, Koppal, India
}

\author{
Seema B. N.* \\ Department of Obstetrics and Gynecology, KIMS, Koppal, Karnataka, India \\ Received: 09 July 2017 \\ Accepted: 20 July 2017 \\ *Correspondence: \\ Dr. Seema B. N., \\ E-mail: drseemabn@gmail.com \\ Copyright: (C) the author(s), publisher and licensee Medip Academy. This is an open-access article distributed under \\ the terms of the Creative Commons Attribution Non-Commercial License, which permits unrestricted non-commercial \\ use, distribution, and reproduction in any medium, provided the original work is properly cited.
}

\begin{abstract}
Background: Anemia is the nutritional deficiency disorder and 56\% of all women living in developing countries are anaemic according to World Health Organization. India has the highest prevalence of anaemia and $20 \%$ of total maternal deaths are due to anemia. To determine the prevalence of anemia and factors influencing its causation among pregnant women.

Methods: This is the study of 1769 pregnant women which was conducted in a rural population of Koppal district, Karnataka, India, from June 2016 to November 2016 i.e. a period of 6 months. This longitudinal prospective observational study was conducted in the district hospital of Koppal. Anemia was classified as per the Indian Council of Medical Research (ICMR) criteria. The diagnosis of anemia was undertaken by peripheral blood smear examination and standard hemoglobin estimation by shale's method.

Results: The average age of pregnant women was 23.5 years, ranging between 18 and 40 years. Most of the women belonged to below poverty line (BPL) families (84.6\%) and Hindu religion (98\%). Regarding education, $28.9 \%$ were illiterates. The mean haemoglobin level was found to be 8.95 . Prevalence of anemia was $96.5 \%$ among the pregnant females in this region of rural Koppal. Out of these $22.47 \%$ had mild anemia, $56.30 \%$ had moderate anemia, $14.98 \%$ had severe anemia and $2.73 \%$ very severe anemia according to ICMR classification of anemia.

Conclusions: High prevalence of anemia among pregnant women indicates anemia to be a major public health problem in the rural community and indicates strict implementation of National Nutrition Anemia prophylaxis programme. Factors such as socioeconomic status, education, birth interval, and gravida contribute to this high prevalence.
\end{abstract}

Keywords: Anemia, Pregnancy, Rural

\section{INTRODUCTION}

Anaemia is the nutritional deficiency disorder and $56 \%$ of all women living in developing countries are anaemic (World Health Organization). ${ }^{1}$ It is the most common haematological disorder during pregnancy. Prevalence of anaemia in South Asian countries is among the highest in the world, and India has the highest prevalence of anaemia (87\%). According to the reports of World Health Organization, in developing countries, $35 \%$ to $75 \%(56 \%$ on average) of pregnant women and, in industrialized countries, $18 \%$ of women are anemic., ${ }^{2,3}$ Anaemia is known to be associated with multiple factors, such as poor socioeconomic status, high parity, short birth interval, poor diet both in quantity and quality, lack of health and nutrition awareness, and a high rate of infectious diseases and parasitic infestations. In developing countries, underprivileged people have often limited access to medical care and preventive measures, increasing their risk of becoming anemic and contributing to high maternal mortality. ${ }^{3-5}$ Studies about the prevalence of anemia among pregnant women in this area 
are few, so this study was conducted to know the prevalence of anemia in pregnancy in rural Koppal district.

\section{METHODS}

This is the study of 1769 pregnant women which was conducted in a rural population of Koppal district, Karnataka, India, from June 2016 to November 2016 i.e. a period of 6 months. This longitudinal prospective observational study was conducted in the district hospital of Koppal. Pregnant women using antenatal care services at the district hospital were taken as the source population. While the study population was women after 37 weeks of gestation who either visited the OPD for routine antenatal check-up or were admitted for delivery. We excluded women who were not term i.e. gestational age of less than 37 completed weeks, non-singleton pregnancies, with defined congenital malformations and maternal diabetes. After institutional ethical clearance, 1769 pregnant women were enrolled in the study after taking written consent from the participants. The data were recorded in a pretested and semi structured questionnaire by the interview technique. The diagnosis of anaemia was estimated by using the standard peripheral blood smear examination and shale's acid haematin method of Haemoglobin estimation. The hemoglobin levels of $>11 \mathrm{mg} / \mathrm{dL}$ was considered as normal, $10-11 \mathrm{mg} / \mathrm{dL}$ as mild, $7-9.9 \mathrm{mg} / \mathrm{dL}$ as moderate, and $<7 \mathrm{mg} / \mathrm{dL}$ as severe anemia as recommended by the Indian Council of Medical Research (ICMR).

\section{Statistical analysis}

Data were analyzed using SPSS version 17.0 and chi square test for categorical data were performed. $\mathrm{P}<0.05$ was considered statistically significant.

\section{RESULTS}

A total of 1769 pregnant women participated in this study. The average age of pregnant women was 23.5 years, ranging between 18 and 40 years. Most of the women belonged to below poverty line (BPL) families $(84.6 \%)$ and Hindu religion (98\%). Regarding education, $28.9 \%$ were illiterates and $8.6 \%, 20.6 \%, 28 \%$, and $13.7 \%$ had completed primary, middle, high school and graduates respectively. Regarding gravidity, $43.7 \%$ pregnancies were of primigravida, $35.8 \%$ second gravida, $14.8 \%$ third gravid, and $6.2 \%$ multigravida. $83.5 \%$ were from rural areas and $13.5 \%$ were from urban areas (Table $1)$.

Table 1: Association of various demographic factors with anemia in pregnant women.

\begin{tabular}{|c|c|c|c|c|c|c|c|c|c|c|c|}
\hline \multirow{2}{*}{$\begin{array}{l}\text { Variables } \\
\text { Age/Years }\end{array}$} & \multirow{2}{*}{$\begin{array}{l}\text { Total no. of } \\
\text { patients } \\
\text { No }\end{array}$} & \multicolumn{2}{|c|}{$\begin{array}{l}\text { Normal } \\
(>11)\end{array}$} & \multicolumn{2}{|c|}{$\begin{array}{l}\text { Mild anemia } \\
(10-10.9)\end{array}$} & \multicolumn{2}{|c|}{$\begin{array}{l}\text { Moderate } \\
\text { anemia (7-9.9) }\end{array}$} & \multicolumn{2}{|c|}{$\begin{array}{l}\text { Severe anemia } \\
(4-6.9)\end{array}$} & \multicolumn{2}{|c|}{$\begin{array}{l}\text { Very Severe } \\
\text { anemia }(>4)\end{array}$} \\
\hline & & No & $\%$ & No & $\%$ & No & $\%$ & No & $\%$ & No & $\%$ \\
\hline $15-20$ & 389 & 68 & 17.5 & 89 & 22.9 & 175 & 45.0 & 51 & 13.1 & 6 & 1.5 \\
\hline $21-25$ & 931 & 190 & 20.4 & 174 & 18.7 & 450 & 48.3 & 101 & 10.8 & 16 & 1.7 \\
\hline $26-30$ & 360 & 74 & 20.6 & 57 & 15.8 & 162 & 45.0 & 55 & 15.3 & 12 & 3.3 \\
\hline$>30$ & 89 & 20 & 22.5 & 10 & 11.2 & 40 & 44.9 & 13 & 14.6 & 6 & 6.7 \\
\hline \multicolumn{12}{|l|}{ Gravidity } \\
\hline G1 & 774 & 176 & 22.7 & 195 & 25.2 & 363 & 46.9 & 40 & 5.2 & 0 & 0.0 \\
\hline G2 & 624 & 142 & 22.8 & 134 & 21.5 & 321 & 51.4 & 27 & 4.3 & 0 & 0.0 \\
\hline G3 & 263 & 46 & 17.5 & 49 & 18.6 & 135 & 51.3 & 31 & 11.8 & 2 & 0.8 \\
\hline $\mathrm{G}>4$ & 108 & 19 & 17.6 & 18 & 16.7 & 63 & 58.3 & 8 & 7.4 & 0 & 0.0 \\
\hline \multicolumn{12}{|l|}{ Residence } \\
\hline Urban & 292 & 58 & 19.9 & 67 & 22.9 & 152 & 52.1 & 14 & 4.8 & 1 & 0.3 \\
\hline Rural & 1477 & 311 & 21.1 & 339 & 23.0 & 727 & 49.2 & 99 & 6.7 & 1 & 0.1 \\
\hline \multicolumn{12}{|l|}{ Education } \\
\hline Primary & 153 & 32 & 20.9 & 28 & 18.3 & 81 & 52.9 & 12 & 7.8 & 0 & 0.0 \\
\hline Middle School & 366 & 68 & 18.6 & 84 & 23.0 & 196 & 53.6 & 17 & 4.6 & 1 & 0.3 \\
\hline High School & 496 & 110 & 22.2 & 116 & 23.4 & 243 & 49.0 & 27 & 5.4 & 0 & 0.0 \\
\hline Graduate/ PG & 242 & 78 & 32.2 & 59 & 24.4 & 97 & 40.1 & 8 & 3.3 & 0 & 0.0 \\
\hline Illiterate & 512 & 92 & 18.0 & 118 & 23.0 & 260 & 50.8 & 41 & 8.0 & 1 & 0.2 \\
\hline \multicolumn{12}{|c|}{ Socioenocomic status } \\
\hline APL & 272 & 56 & 20.6 & 65 & 23.9 & 137 & 50.4 & 14 & 5.1 & 0 & 0.0 \\
\hline BPL & 1497 & 314 & 21.0 & 338 & 22.6 & 737 & 49.2 & 97 & 6.5 & 11 & 0.7 \\
\hline
\end{tabular}


The mean haemoglobin level was found to be 8.95. Only $3.5 \%$ of the total pregnant female at term had hemoglobin above $11 \mathrm{mg} / \mathrm{dl}$. So, prevalence of anemia was $96.5 \%$ among the pregnant females in this region of rural Koppal. Out of these $22.47 \%$ had mild anemia, $56.30 \%$ had moderate anemia, $14.98 \%$ had severe anemia and $2.73 \%$ very severe anemia according to ICMR classification of anemia.

The prevalence of anemia in pregnant females in the age group $15-20$ years was $82.5 \%$. Out of the total anemic women in this age group $22.9 \%$ had mild anemia, $45 \%$ had moderate anemia, $13.1 \%$ had severe anaemia and $1.5 \%$ had very severe anemia in this age group. $17.5 \%$ had haemoglobin $>11 \mathrm{gm}$ in this group. Similarly, majority of women in the age group 20-25 years $(79.6 \%)$ and $26-30$ years $(79.4 \%)$ had mild to moderate anemia. Whereas in women over the age of $>30$ years, the prevalence was of anaemia was $77.5 \%$. Among these, $14.6 \%$ and $6.7 \%$ had severe and very severe anemia respectively.

Although the overall prevalence of anemia did not vary significantly with literacy level, the severity of anemia differs to a great extent. $8.2 \%$ of total illiterate pregnant females had very severe anemia whereas no case of very severe anemia was found among graduates and post graduates. $24.4 \%$ of women educated up to graduate or post-graduate levels had only mild anemia, $40.1 \%$ had moderate anemia and only $3.3 \%$ had severe anemia. The corresponding figures in the illiterate women were $23.0 \%, 50.8 \%$ and $8.0 \%$ respectively. Most women educated either upto primary and secondary level had mild (18.3. and 23.0\%), moderate anaemia (52.9 and $53.6 \%$ ) with prevalence of severe anaemia being $7.8 \%$ and $4.6 \%$ respectively.

The parity of the pregnant female was associated with the severity of anemia. $23.5 \%$ cases of severe anemia and 2 cases of very severe anemia were present in multiparous women. Majority of nulliparous or primiparous women had mild to moderate anemia.

\section{DISCUSSION}

Anemia is the most common nutritional deficiency disorder in the world. When compared with other developing countries, India shows higher prevalence of anemia in all the groups.

In this study, the prevalence of anemia in pregnant women was $96.5 \%$, as also reported by Kaul et al and Mangal $\mathrm{M}$ et al in rural Harayana in their study observed a very high prevalence of anemia i.e $91 \%$ and $98 \%$ respectively. ${ }^{6,7}$ The mean hemoglobin level of pregnant women in this study was found to be $8.95 \mathrm{~g} \%$, ranging from 5 to $15 \mathrm{~g} \%$, which is similar to that in the study by Mangal M et al. ${ }^{7}$
The reasons for high prevalence of anemia in this area are various. The high prevalence of anemia can be attributed to low dietary iron and folic acid intake or deprived bioavailability of iron or chronic blood loss owing to infections. Women in rural areas rarely get to choose when they can marry, or regarding timings and spacing of child birth. Majority of women in our country are vegetarians. Irregular ANC visits by pregnant patients because of Lack of proper means of transport, poor condition of roads and inadequate medical facilities available in rural areas are some of the reasons for high prevalence in this area.

In this study, the prevalence of mild, moderate, and severe anemia was observed as $22.47 \%, 56.3 \%$, and $14.98 \%$, respectively, which is comparable with the studies conducted by Sharma et al in Rajasthan and by Wadgav HV. ${ }^{8,9}$ Poverty, ignorance, and non-availability or failure to utilise available medical facilities can be contributing to various degree of anemia.

Anemia was predominantly seen among pregnant women belonging to BPL families compared with APL families. Similar observation was made in a study conducted by Lokare et al. ${ }^{10}$ Improvement in health-care delivery system with health education targeting improved utilization of availability of healthcare facilities at the beneficiary door steps will help in reducing anemia prevalence. Hemoglobin level of pregnant women seemed to have a negative correlation with gravid. Gatea et al reported similar observation among pregnant women in Baghdad. ${ }^{11}$ Increased requirement of iron with repeated pregnancy had contributed to the decreased hemoglobin levels. Anemia was found to be more in uneducated group in this study. The impact of literacy status on anemia was also studied by Dutta et al and was found to be significant. ${ }^{12}$

Present study had certain limitations. Only patients coming to a single medical centre were included in this study. Patients in other parts of rural Koppal may be having different prevalence of anaemia and different socio demographic factors contributing to the same.

\section{CONCLUSION}

A high prevalence of anemia (64\%) indicates that the anemia continues to be a major public health problem in rural area. Socioeconomic status, literacy of women, gravida, and birth interval are the major determinants that contribute to the problem of anemia. All practitioners handling obstetrics cases should be motivated for prescribing iron preparations and balanced diet with good compliance.

\section{Funding: No funding sources Conflict of interest: None declared \\ Ethical approval: The study was approved by the Institutional Ethics Committee}




\section{REFERENCES}

1. Rajamouli J, Ravinder A, SCK Reddy, Sujatha Pambi. Study on prevalence of anemia among pregnant women attending antenatal clinic at rural health training centre (RHTC) and chalmeda anand rao institute of medical sciences teaching hospital, Karimnagar, Telangana, India. Int J Contemp Med Res. 2016;3(8):2388-91.

2. Sari M, de Pee S, Martini E, Herman S, Sugiatmi, Bloem MW, Yip R. Estimating the prevalence of anaemia: a comparison of three methods. Bull World Health Organ. 2001;79:506-11.

3. Suryanarayana R, Santhuram AN, Chandrappa M, Shivajirao P, Rangappa SS. Prevalence of anemia among pregnant women in rural population of Kolar district. Int J Med Sci Public Health. 2016;5:454-8.

4. Dey S, Goswami S, Goswami M. Prevalence of anemia in women of reproductive age in Meghalaya: a logistic regression analysis. Turk J Med Sci. 2010;40:783-9.

5. Srinivasa Rao P, Srikanth S. Prevalence of anemia in the first trimester of pregnancy in rural population of Krishna district in Andhra Pradesh. Sch J App Med Sci. 2013;1:570-4.

6. Kaul R, Ahmad J, Baba TA, Sheikh S, Ahmad A, Ashraf M. Anaemia in pregnant women in a rural block of Kashmir valley: its prevalence and sociodemographic associates. Int J Med Sci Public Health. 2013;2:814-8.
7. Mangla M, Singla D. Prevalence of anaemia among pregnant women in rural India: a longitudinal observational study. Int J Reprod Contracept Obstet Gynecol. 2016;5:3500-5.

8. Sharma P, Mehta S, Nagar R. Prevalence of anemia and sociodemographic factors associated with anemia among pregnant women attending antenatal hospital in Jaipur City India. IOSR J Pharm Biol Sci. 2013;6:1-5.

9. Wadgave HV. Burden of anemia among the pregnant women in rural Area. Healthline. 2011;2:76-7.

10. Lokare PO, Karanjekar VD, Gattani PL, Kulkarni AP. A study of prevalence of anemia and sociodemographic factors associated with anemia among pregnant women in Aurangabad city, India. Ann Nigerian Med. 2012;6:30-4.

11. Gatea AA, Tawfeeq WF, Hasan MR. The prevalence of iron deficiency anemia among pregnant women in Ibn-Albaldy Hospital. Iraq Natl J Nurs Specialties. 2013;26(1):71-9.

12. Dutta PK, Nagraj T, Gopinath VP. A case control study of anemia in pregnancy. Ind $\mathrm{J}$ Preventive Social Med. 1992;23(1):1-5.

Cite this article as: Seema BN. Prevalence of anemia among pregnant women in rural Koppal: a study from teaching hospital, Koppal, India. Int J Reprod Contracept Obstet Gynecol 2017;6:3792-5. 